\title{
INFLUENCE OF SEDENTARY BEHAVIOUR ON POSTURE SYMMETRY AND TYPE AMONG 4-7-YEAR-OLD CHILDREN IN RIGA
}

\author{
Liene Martinsone-Bērzkalne, Silvija UmbrašKo, \\ ILVA DuL̨EVSKA \\ Riga Stradiňš University, Institute of Anatomy and Anthropology, \\ Department of Morphology, Riga, Latvia
}

\begin{abstract}
Physical inactivity, screen time and sedentary behaviour among young children is increasing. These factors have an impact on future health conditions increasing the risk of metabolic, cardiovascular and posture diseases. The World Health Organization has issued the guidelines on physical activity, sedentary behaviour and sleep for children of less than 5 years of age that shows contributing factors for healthy individuals starting from early childhood.

Only few studies show the true state of posture diseases among preschool children. In our study we tried to find the problems of posture symmetry and type among young children for first time in Latvia.

The conclusions after the study were similar to tendencies in the world. The posture disorders and asymmetrical posture increased with the age of children and sedentary behaviour (TV and computer) had a negative impact on the posture status.
\end{abstract}

Keywords: posture symmetry; posture type; sedentary behaviour; preschool children

\section{INTRODUCTION}

Physical inactivity has been identified as a leading risk factor for global mortality and a contributor to the increase in overweight and obesity [9]. Early childhood ( $<5$ years) is a period of rapid physical and congenital development, and this is the time period during which a child's habits are formed and family 
lifestyle routines are open to changes and adaptations [8]. Physical inactivity has a negative impact on health, including overweight, obesity, risk of cardiovascular disease in the adulthood, metabolic syndrome and posture disorders. The digital world has come to stay and is even evolving with the availability of smartphones and tablets with at least $96 \%$ of families owning at least one TV set and $36 \%$ of children aged 8 years having one of these devices in their bedroom [3]. Increased time of TV watching, desktop/laptop computer use, electronic gaming is associated with pain and discomfort in the musculoskeletal system $[1,4,6]$. There are few studies that show the impact on younger children. The World Health organization guidelines recommend that, in the age group of 3-4 years, physical activities should be performed at least 180 minutes of which at least 60 minutes are moderate to vigorous. Sedentary screen time should be limited to up to 60 minutes and good quality sleep should be 10-13 hours.

The aim of present study was to identify the posture type and symmetry and posture disorders among 4-7-year-old children according to sedentary behaviours (TV watching and computer use).

\section{MATERIALS AND METHODS}

Our study involved 959 children from 22 preschool educational institutions from Riga region. The age of the children was $4-7$ years. The conduct of the study was coordinated with the head of each preschool educational institution. Informed consent was received from parents before the child was included in the study. Parents filled a questionnaire about the birth of their child, development, physical activities, and sedentary behaviours (TV watching, computer use). As the second step, children were measured in the nurse's office of the preschool educational institutions. The measurements were performed by trained personnel of the Anthropology Office from Riga Stradiňš University Institute of Anatomy and Anthropology. The measurements were performed from 9:00-12:00 a.m. The data were fixed in the protocol. The conclusions about posture type and symmetry were made based on the questionnaire and measurements. All parents received feedback information on conclusions and recommendations.

The data analysed from the questionnaire included the child's gender, year of birth and the date when the anthropometric measurements were performed (the actual age of child was calculated according to the date when the anthropometric measurements were collected), data about physical activities, duration of TV watching and computer use. Posture symmetry was calculated according to the following parameters: the height of shoulders $(\mathrm{cm})$, asymmetry of the 
length of legs according to the skin folds ( $\mathrm{cm}$ ), rhombus between C7, angulus inferior scapulae dextra et sinistra and L5 vertebra $(\mathrm{cm})$, distance between scapula and vertebral column $(\mathrm{cm})$, asymmetry of scapulae $(\mathrm{cm})$. According to the obtained data, posture symmetry was divided into four stages. If the asymmetry was less than $0.5 \mathrm{~cm}$ in every parameter, it was symmetrical posture. If the asymmetry was up to $1 \mathrm{~cm}$ in 1-4 parameters, then it was mild asymmetry. If the asymmetry was higher than $1 \mathrm{~cm}$ in 1-6 parameters, it was moderate asymmetry. If the asymmetry was higher than $2 \mathrm{~cm}$ in $1-6$ parameters, it was typical asymmetry, suspected scoliotic posture [7].

The type of posture was determined according to the evaluation of posture in the sagittal plane; the head position, cervical lordosis $(\mathrm{cm})$ and lumbar lordosis $(\mathrm{cm})$ were analysed. The classification of posture types was used according to Prof. Aleksandrs Biezins' methodological letter (1986): ideal posture, kyphotic posture, lordotic posture, kyphotic-lordotic posture.

The anthropometric measurements were performed according to the methods of R. Martin, K. Saller and J. Primanis (1937).

\section{RESULTS}

The subjects of our study included $53.3 \%$ of girls $(n=511)$ and $46.7 \%$ of boys $(\mathrm{n}=448)$. There were $98 \%$ of children $(\mathrm{n}=976)$ who were engaged in physical activities in the preschool educational institution but $1.7 \%$ of children were not. The parents of three children did not answer this question.

There were $59.1 \%$ of children $(n=565)$ who were engaged in physical activities outside the preschool educational institution, but $40.9 \%(\mathrm{n}=391)$ of children were not engaged in physical activities outside the kindergarten. The parents of three children did not answer this question.

The posture symmetry and the posture type were analysed. Symmetrical posture was determined in $23.9 \%$ of children $(n=229)$, but asymmetrical posture was determined in $76.1 \%$ of children $(\mathrm{n}=729)$. The asymmetrical posture then was divided into stages. Mild asymmetry was identified in $45.3 \%$ of children $(n=434)$, moderate asymmetry in $29.0 \%$ of children $(n=278)$ and typical asymmetry in $1.8 \%$ of children $(\mathrm{n}=17)$. Posture symmetry was also analysed in each age group. The prevalence of symmetrical posture was $34.4 \%$ $(\mathrm{n}=73)$ in the group of 4-year-old children and 15.5\% $(\mathrm{n}=30)$ in the group of 7 -year-old children $(\mathrm{p}=0.001)$. The stages of asymmetrical posture were analysed in each age group. Moderate and typical asymmetry of posture increased with increase in age. Moderate asymmetry of posture was $17.0 \%(n=36)$ in the group of 4-year-old children but $39.9 \%(n=77)$ in the group of 7 -year-old 
children. Typical asymmetry of posture was in $0.5 \%(\mathrm{n}=1)$ in the group of 4 -year-old children and $2.6 \%(n=5)$ in the group of 7 -year-old children. The symmetrical posture was also analysed according to the gender: symmetrical posture was identified in $26.3 \%$ of girls and $21.2 \%$ of boys $(\mathrm{p}=0.288)$.

The type of posture was analysed. Ideal posture was identified in $41.3 \%$ of children $(\mathrm{n}=396)$ included in the study. Abnormal posture was identified in $58.7 \%$ of children $(\mathrm{n}=562 ; \mathrm{p}=0.001)$. Kyphotic posture was identified in $18.6 \%$ of children $(n=178)$, lordotic posture was identified in $18.8 \%(n=180)$, and kyphotic-lordotic posture was identified in $21.3 \%$ of children $(n=204)$.

The type of posture in the age groups was analysed. Ideal posture was identified in $51.3 \%$ of children $(n=109)$ of the group of 4 -year-old children, but it decreased to $36.8 \%(\mathrm{n}=71)$ in the group of 7 -year-old children. The type of abnormal posture was specific to each age group. The kyphotic posture $18.4 \%(\mathrm{n}=39)$ was most common in the 4 -year-old children. The kyphoticlordotic posture was most common in the 5 -year-old $(20.4 \%, \mathrm{n}=57)$, 6 -yearold $(26.0 \%, \mathrm{n}=71)$ and 7 -year-old $(23.8 \%, \mathrm{n}=46)$ children $(\mathrm{p}=0.030)$. The type of posture was also analysed according to the gender: the standard posture was identified in $42.7 \%$ of girls and $39.7 \%$ of boys ( $p=0.208$ ).

Next, the association between the posture type and computer use was analysed. The standard posture was identified in $36.5 \%$ of children $(n=172)$ who used the computer and $46.2 \%(n=224)$ children who did not use it. The children who used the computer had the kyphotic posture 2.9 percentage points more frequently, the lordotic posture 5.3 percentage points more frequently and the kyphotic-lordotic posture 1.5 percentage points more frequently $(\mathrm{p}=0.016$, Figure 1$)$.

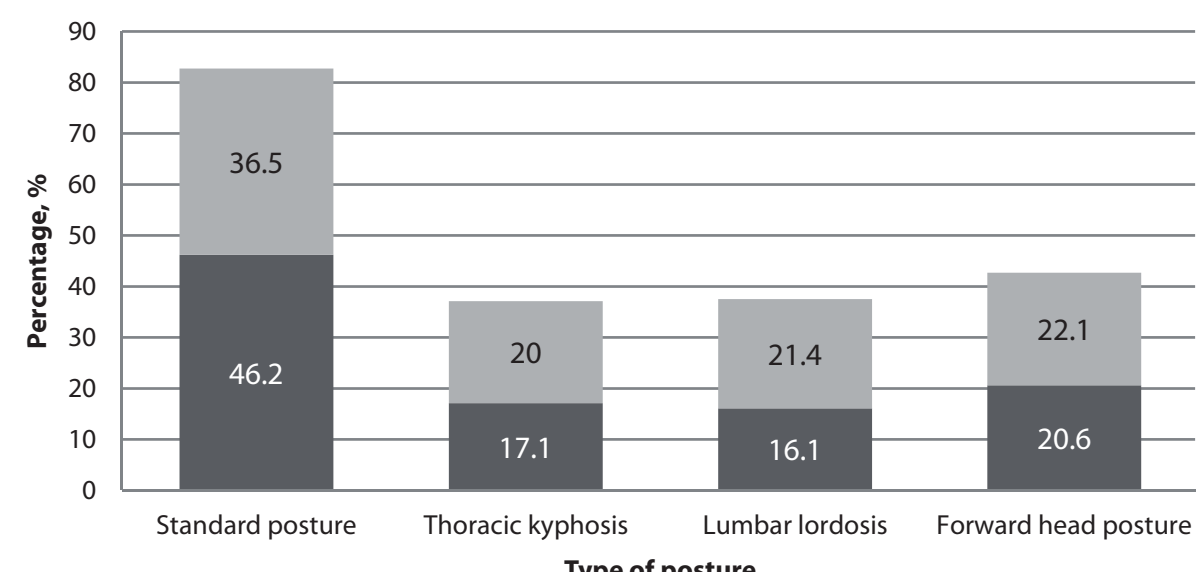

Type of posture

- Not using a computer $(\mathrm{n}=485)$ Using a computer $(\mathrm{n}=471)$

Figure 1. Distribution of standard posture and posture types according to computer use. 
The association between posture symmetry and computer use showed that the symmetrical posture was identified in $21.4 \%$ of children $(\mathrm{n}=101)$ who used the computer and in $26.4 \%(n=128)$ who did not use it. Mild asymmetry was identified 0.6 percentage points more frequently, moderate asymmetry 3.2 percentage points more frequently and typical asymmetry 0.2 percentage points less frequently in the group of children who used the computer $(\mathrm{p}=0.302$, Figure 2$)$.

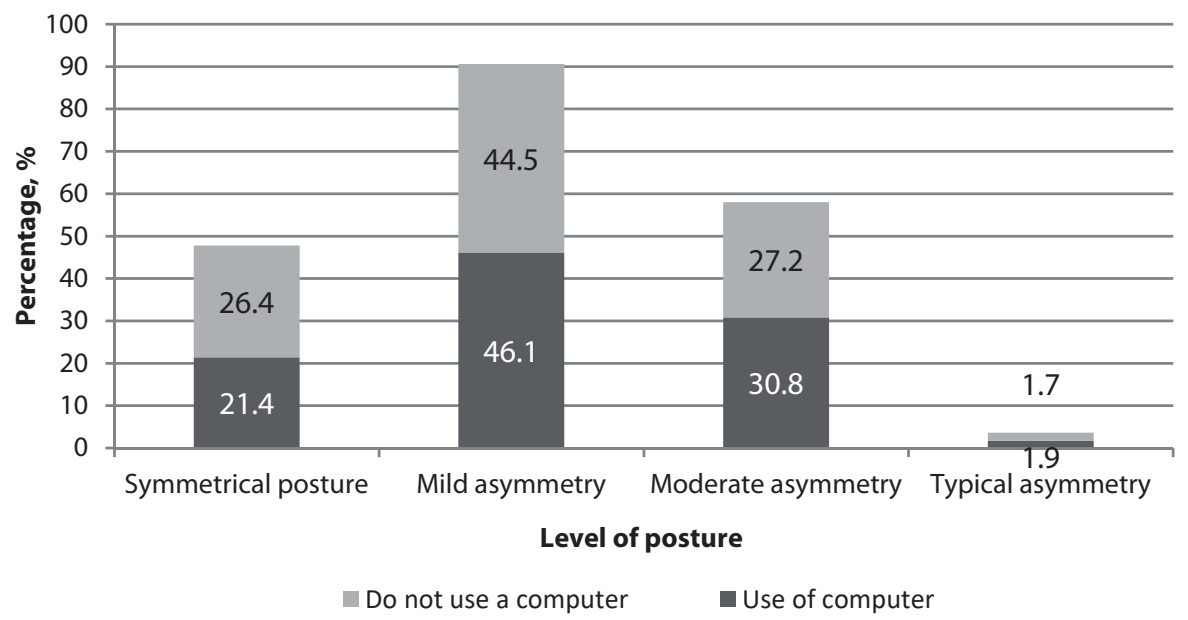

Figure 2. Distribution of posture asymmetry according to computer use.

The association between posture type and TV watching over 1 hour a day was analysed. The standard posture was identified in $40.4 \%$ of children $(n=180)$ who watched TV over 1 hour a day and in $42.3 \%$ of children $(\mathrm{n}=216)$ who watched TV less than 1 hour a day. In the group of children who watched TV over 1 hour a day, the kyphotic posture was identified 0.7 percentage points more frequently and the kyphotic-lordotic posture 5.0 percentage points more frequently. In the group of children who watched TV less than 1 hour a day the lordotic posture was identified 3.9 percentage points more frequently $(\mathrm{p}=0.168$, Figure 3$)$. 


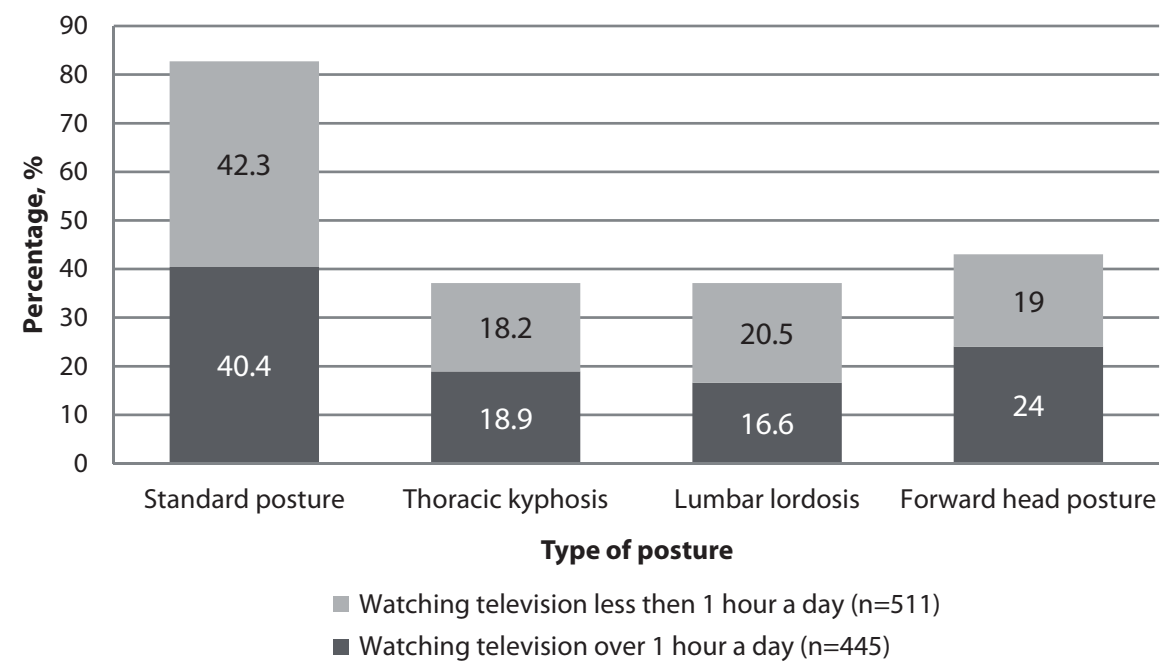

Figure 3. Distribution of standard posture and posture types according to TV watching.

The association between posture symmetry and watching TV over 1 hour a day was also analysed. Symmetrical posture was identified in $22.9 \%$ of children ( $\mathrm{n}$ $=102)$ who watched TV over 1 hour a day and in $24.9 \%$ of children $(n=127)$ who watched TV less than 1 hour a day. In the group of children who watched TV over 1 hour a day, mild asymmetry was identified 1.2 percentage points more frequently, and typical asymmetry was identified 0.8 percentage points more frequently. In the group of children who watched TV less than 1 hour a day, moderate asymmetry was identified 1.2 percentage points more frequently $(\mathrm{p}=0.615$, Figure 4$)$.

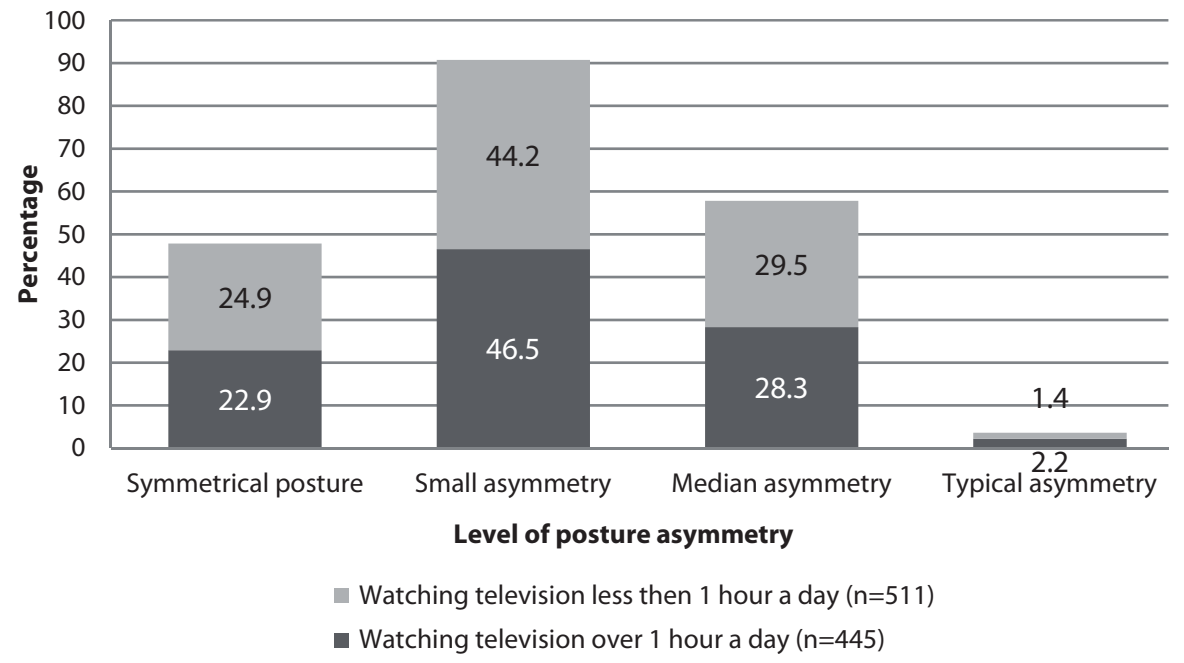

Figure 4. Distribution of posture asymmetry according to TV watching. 
Finally, the combined influence of TV watching and computer use and the posture of children was analysed. In the group of children who watched TV over 1 hour a day and used the computer, the symmetrical posture was identified in $15.8 \%$ of children $(n=29 ; \mathrm{p}=0.003)$. In the group of children who watched TV less than 1 hour a day and did not use the computer, the symmetrical posture was identified in $24.7 \%$ of children $(n=55 ; p=0.890)$. In the group of children who watched TV over 1 hour a day and used the computer, the symmetrical posture was identified in $37.0 \%$ of children $(n=68 ; p=0.207)$. In the group of children who watched TV less than 1 hour a day and did not use the computer, the symmetrical posture was identified in $50.0 \%$ of children $(\mathrm{n}=112 ; \mathrm{p}=0.002$; Figure 5$)$.

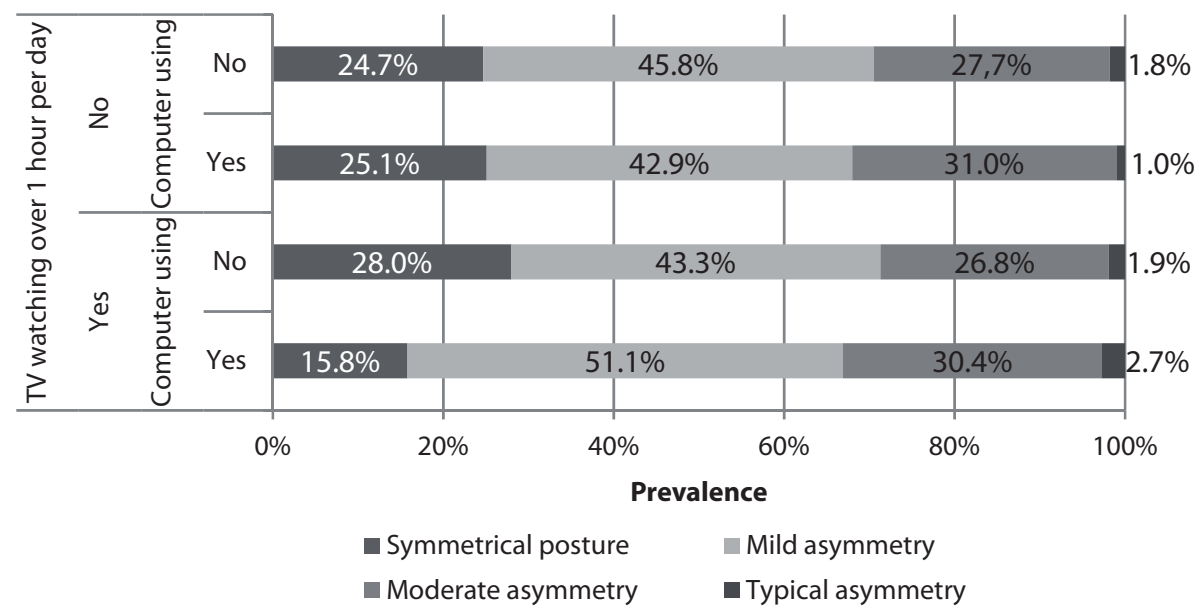

Figure 5. Relations between TV watching and computer use and prevalence of posture symmetry.

\section{DISCUSSION}

The data are a part of the study of anthropometric measurements of preschool children in Riga region, and it is the first study in the history of anthropology in Latvia when preschool children are the main objects in an anthropometric study.

Worldwide, there are few studies that demonstrate the changes of musculoskeletal system in preschool children. Straker et al. (2008) examined tablet usage in younger children. During tablet use, 5-6-year-old children had fewer neutral spinal postures, but greater posture variation as compared to desktop computer or pencil and paper use [5]. In our study we compared the age groups 
of 4- and 7-year-old children, and in almost all data we concluded that posture type disorders increase with the age of child. In the study of Howie et al. (2017), the conclusion on musculoskeletal impact was that children playing with tablets had greater body segment posture variation and transition between sitting and other gross body postures than during TV watching but less than playing with toys [2]. In our study, we concluded that our children had the tendency to have more typical posture disorders if they watch TV over 1 hour a day. Computer use significantly affects posture type and resulted in more frequent posture disorders in the group of children who used the computer.

Sport activities in preschool educational institutions at least 3-4 times per week, physical activities during the weekend and family habits can improve the negative tendency of posture disorders in Riga preschool educational institutions.

\section{REFERENCES}

1. Balague F., Troussier B., Salminen J.J. (1999). Non-specific low back pain in children and adolescents: risk factors. Eur Spine J, 8, 429-438. https://doi. org/10.1007/s005860050201

2. Howie E.K., Coenen P., Campbell A.C., Ranell S., Straker L.M. (2017). Head, trunk and arm posture amplitude and variation, muscle activity, sedentariness and physical activity of 3- to 5-year-old children during tablet computer use compared to television watching and toy play. Applied Ergonomics, 65, 41-50. https://doi.org/10.1016/j.apergo.2017.05.011

3. Rideout V. (2013). Zero to eight: children's media use in America 2013. A common sense media research study. https://commonsensemedia.org/research/ zero-to-eight-childrens-media-use-in-america-2013. Published October 28, 2103. Accessed April 10, 2020.

4. Shan Z., Deng G., Li J., Li Y., Zhang Y., Zhao Q. (2013). Correlation analysis of neck/shoulder pain and low back pain with the use of digital products, physical activity and physiological status among adolescents in Shanghai. PLoS One, 8 (10), e78109. https://doi.org/10.1371/journal.pone.0078109

5. Straker L., Coleman J., Skoss R., Maslen B., Burgess-Limerick R., Pollock C. (2008). A comparison of posture and muscle activity during tablet computer, desktop computer and paper use by young children. Ergonomics, 51, 540-555. https://doi.org/10.1080/00140130701711000

6. Straker L., Abbott R., Collins R., Campbell A. (2014). Evidence-based guidelines for wise use of electronic games by children. Ergonomics, 57, 471-489. https:// doi.org/10.1080/00140139.2014.895856 
7. Umbraško S. (2005). Skolēnu stājas un pēdas parametru vērtējums kā fiziskās attīstības rādītājs gadsimtu mijā. Promocijas darbs. Riga, 2005, 172.

8. Willumsen J., Bull F. (2020). Development of WHO Guidelines on physical activity, sedentary behaviot, and sleep for children less the 5 years of age. Journal of physical activity and health, 17, 96-100. https://doi.org/10.1123/ jpah.2019-0457

9. World Health Organisation (2019). Guidelines of physical activity, sedentary behaviour and sleep for children under 5 years of age. WHO, Switzerland.

\section{Address for correspondence:}

Liene Martinsone-Bērzkalne

Kronvalda bulvāris 9, Riga, Latvia, LV-1010

Phone: + 37126343727

E-mail: liene.martinsone@gmail.com 